\title{
Study on the Optimal Path Optimization of Coal Transportation based on Cost Minimization
}

\author{
Mingfang.li \\ Hebei University of science and technology \\ Shijiazhuang, Hebei, China \\ Yuxiang Street 26, Yuhua district, Shijiazhuang, Hebei, \\ China
}

\author{
Shumin Lin* \\ Hebei University of science and technology \\ Shijiazhuang, Hebei, China \\ Yuxiang Street 26, Yuhua district, Shijiazhuang, Hebei, \\ China \\ 1027377546@qq.com
}

\begin{abstract}
China is a country with abundant coal resources, most provinces and regions are more or less the existence of coal resources, coal size also can be formed, however, are mainly distributed in China's western region of shanxi, shanxi and Inner Mongolia and other regions. And in terms of consumption, they are mainly concentrated in the economy relatively developed provinces, such as the Beijing and Tianjin tang, LiaoZhong south, shanghai-Nanjing Hangzhou and the pearl river delta industrial base, the area of coal consumption as long as from the demand for electricity. For the current situation of the different parts of the coal production and marketing and cross-regional transportation of coal laid the inevitability, makes our country have formed a unique " north coal south" and "west to east" coal transport characteristics. Therefore, electric coal production and power generation in China face a serious transportation problem in adverse distribution area. This problem will also become one of the factors that influence China's realization of the Chinese dream. In this paper, a genetic algorithm based on cost minimization control is proposed to solve this problem.
\end{abstract}

Keywords-Electric coal; transportation route; Cost minimization; Genetic algorithm

\section{INTRODUCTION}

The characteristics of different regions of coal production and marketing in China have resulted in the large number of coal transport nodes, the distance between transportation and the consumption of power plants, so that the coal transport costs remain high. As countries continue to transport infrastructure investment, especially in the mode of railway transportation, the railway line and transport ability has greatly improved, but with the increasing of coal consumption, the current coal transport capacity and transport plan is still there is a big gap [1].

Genetic algorithm (ga) is mimic natural biological evolution and the gradually mature of a kind of stochastic global search optimization method, the global optimization method inherits the genetics and evolution of the research. The genetic algorithm is a kind of random searching method, which has the characteristics of transcending and other searching methods, which is characterized by high efficiency, parallel search and global character. Genetic algorithm in searching the optimal solution will continue to expand and optimize the content of the solution space, at the same time improve the adaptability of search automatically adjust the search process, depending on the search process using the theory of evolution principle of survival of the fittest in the screening of the feasible solution to find the optimal solution, and then get a similar optimization scheme. By using the genetic algorithm to find the best scheme, each generation will be according to oneself to adapt to the value in the field of problem solving, and learn from the genetic evolutionary method of personalized choices, get a close to the approximation to solve the problem [2].

Choice of genetic algorithm by imitating evolution and genetics of genes in the phenomenon such as reproduction, crossover and mutation, start from any kind of population, by random selection, crossover and mutation operation, will produce more adaptive Cenozoic group, adaptive group appear makes the search domain into a better space of genetic algorithm, after the continuation of the new generation, the final solution space will be gradually reduced to more adaptive the most satisfied with the group, and then a satisfactory solution to the optimization problem [3].

Through the above description of the genetic algorithm, this paper will be based on cost minimization model using coded genetic algorithm (ga), are applied to solve the path optimization problem in transportation, obtain the optimal path of transportation, minimum cost goals are met. In this paper, the specific process can be divided into three parts, first, through the description of coal transportation problem, the costs of coal transport abstraction to each transport nodes and transport path, formed the DHS based on minimizing the total cost of coal company coal transportation route optimization problem; Second, to determine the transport cost and transport capacity under different schemes; Thirdly, according to the ideal solution of NP-hard problem, genetic algorithm is used to solve the problem and obtain the optimized path [4].

\section{THE SPECIFIC PROCESS CAN BE DIVIDED INTO THREE PARTS}

\section{A. Description of the problem of electric coal transport route}

In this paper according to the long-term DHS coal company about the transport path rules make the following arrangements for the transport path: the first step by the coal mining area to highway distribution depot, railway distribution depot or transfer terminal distribution depot; the second step is to select 
a relatively reasonable mode of transportation to the destination [5]. To complete the above two steps, in this paper, the focus will be on how to choose the mode of transportation and logistics node, to minimise the cost under the target of power coal transportation route optimization problem to study.

\section{B. Determination of the cost of different transport programmes}

(1)Determination of transport mileage. Below Table I, Table II, Table III is the transport mileage of logistics nodes in highway, railway and waterway transportation. The specific transport mileage is as follows.

TABLE I TRANSPORT MILEAGE OF LOGISTICS NODES IN HIGHWAY

\begin{tabular}{|c|c|c|c|c|c|c|c|c|c|}
\hline & Chifeng & Jinzhou & Dalian & $\begin{array}{c}\text { Qinhuang } \\
\text { dao }\end{array}$ & $\begin{array}{c}\text { Caofei } \\
\text { dian }\end{array}$ & Tianjin & Qingdao & Lianyungang & Nantong \\
\hline Chifeng & 0 & 275 & 660 & 372 & 436 & 494 & 1014 & 1075 & 1447 \\
\hline Jinzhou & 275 & $\mathbf{0}$ & 389 & 209 & 354 & 455 & 770 & 993 & 1346 \\
\hline Dalian & 660 & 389 & $\mathbf{0}$ & 587 & 721 & 817 & 385 & 608 & 960 \\
\hline Qinhuagdao & 372 & 209 & 587 & $\mathbf{0}$ & 152 & 267 & 785 & 844 & 1204 \\
\hline Caofeidian & 436 & 354 & 721 & 152 & $\mathbf{0}$ & 136 & 639 & 695 & 1054 \\
\hline Tianjin & 494 & 455 & 817 & 267 & 136 & 0 & 542 & 617 & 962 \\
\hline Qingdao & 1014 & 770 & 385 & 785 & 639 & 542 & $\mathbf{0}$ & 228 & 600 \\
\hline Lianyungang & 1075 & 993 & 608 & 844 & 695 & 617 & 228 & $\mathbf{0}$ & 397 \\
\hline Nantong & 1447 & 1346 & 960 & 1204 & 1054 & 962 & 600 & 397 & 0 \\
\hline
\end{tabular}

TABLE II TRANSPORT MILEAGE OF LOGISTICS NODES IN RAILWAY

\begin{tabular}{|c|c|c|c|c|c|c|c|c|c|}
\hline & Chifeng & Jinzhou & Dalian & Qinhuangdao & Caofeidian & Tianjin & Qingdao & $\begin{array}{l}\text { Lianyun } \\
\text { gang }\end{array}$ & Nantong \\
\hline Chifeng & $\mathbf{0}$ & 365 & 971 & 569 & 585 & 548 & 1350 & 1520 & 1802 \\
\hline Jinzhou & 365 & $\mathbf{0}$ & 444 & 200 & 507 & 179 & 924 & 1354 & 1753 \\
\hline Dalian & 971 & 444 & $\mathbf{0}$ & 592 & 840 & 931 & 1417 & 1799 & 2076 \\
\hline Qinhuangdao & 569 & 200 & 592 & $\mathbf{0}$ & 297 & 285 & 724 & 1162 & 1483 \\
\hline Caofeidian & 585 & 507 & 840 & 297 & $\mathbf{0}$ & 264 & 925 & 1150 & 1537 \\
\hline Tianjin & 548 & 179 & 931 & 285 & 264 & $\mathbf{0}$ & 682 & 797 & 1074 \\
\hline Qingdao & 1350 & 924 & 1417 & 1162 & 925 & 982 & $\mathbf{0}$ & 700 & 1001 \\
\hline Lianyungang & 1520 & 1354 & 1799 & 1162 & 1150 & 797 & 700 & $\mathbf{0}$ & 303 \\
\hline Nantong & 1802 & 1753 & 2076 & 1483 & 1537 & 1074 & 1001 & 303 & $\mathbf{0}$ \\
\hline
\end{tabular}

TABLE III TRANSPORT MILEAGE OF LOGISTICS NODES IN WATERWAY

\begin{tabular}{|l|c|c|c|c|c|c|c|}
\hline & Jinzhou & Dalian & Qinhuandao & Caofeidian & Tianjin & Qingdao & Lianyungang \\
\hline Nantong & 1339 & 1022 & 1217 & 1093 & 1367 & 756 & 534 \\
\hline
\end{tabular}

Determination of transport prices. The transportation price of the highway refers to the transportation price of coal in Inner Mongolia in 2016 at 0.74 yuan/ton. According to the investigation, the analysis of railway freight rates can be taken as $0.12,0.15$ and 0.19 respectively. In July 2017, the freight rates of coal transport in Shanghai is 39.6 yuan/ton. According to the above three freight rates can be sorted into table IV. 
TABLE IV TRANSPORT PRICES

\begin{tabular}{|c|c|c|c|c|c|}
\hline \multirow[t]{2}{*}{ Transport mode } & \multirow{2}{*}{$\begin{array}{c}\text { Road transport } \\
\text { (unit: yuan/ton } \\
\text { km) }\end{array}$} & \multicolumn{3}{|c|}{ Railway transport (unit: yuan/ton km) } & \multirow{2}{*}{$\begin{array}{c}\text { Waterway } \\
\text { transport (unit: } \\
\text { yuan/ton) }\end{array}$} \\
\hline & & Regular line & Coal line & Joint railway line & \\
\hline Freight rate & 0.74 & 0.12 & 0.15 & 0.19 & 39.6 \\
\hline
\end{tabular}

(2) The determination of freight forwarding. Transfer cost in general includes the transport in the process of loading, unloading, the fare on the crane handling charge and so on, according to a 2016 various mode of transportation forwarding charges standard, this paper determines the value table $\mathrm{V}$ for the transfer cost.

TABLE V TRANSFER COST

\begin{tabular}{|c|c|c|c|}
\hline & Road transport & Rail transport & $\begin{array}{c}\text { Water } \\
\text { transportation }\end{array}$ \\
\hline Road transport & $\mathbf{0}$ & $\mathbf{5 0}$ & $\mathbf{5 0}$ \\
\hline Rail transport & $\mathbf{5 0}$ & $\mathbf{0}$ & $\mathbf{5 0}$ \\
\hline $\begin{array}{c}\text { Water } \\
\text { transportation }\end{array}$ & $\mathbf{5 0}$ & $\mathbf{5 0}$ & $\mathbf{0}$ \\
\hline
\end{tabular}

Transportation freight (unit: RMB/time)

(3) Determination of maximum transport time. According to the practice of shipping time, the maximum transportation time from the point of departure to the destination is 8 days.

(4) According to the investigation and research on the external cost analysis of transportation, the external cost of this paper can be summarized in table VI.

TABLE VI EXTERNAL COST

\begin{tabular}{|c|c|c|c|}
\hline & $\begin{array}{c}\text { Road } \\
\text { transport }\end{array}$ & Rail transport & $\begin{array}{c}\text { Water } \\
\text { transportation }\end{array}$ \\
\hline $\begin{array}{c}\text { The cost of air } \\
\text { pollution }\end{array}$ & $\mathbf{0 . 1 3 9}$ & $\mathbf{0 . 0 4 1 3}$ & $\mathbf{0 . 0 5 9 9}$ \\
\hline $\begin{array}{c}\text { Noise pollution } \\
\text { cost }\end{array}$ & $\mathbf{0 . 0 0 4 4}$ & $\mathbf{0 . 0 0 2 6}$ & $\mathbf{0 . 0 0 6 7}$ \\
\hline $\begin{array}{c}\text { Accident cost } \\
\text { The total cost }\end{array}$ & $\mathbf{0 . 0 0 1 0 6}$ & $\mathbf{0 . 0 0 0 0 5}$ & $\mathbf{0 . 0 0 1 0 4}$ \\
\hline \multicolumn{2}{|c|}{ External cost summary of transportation mode (unit: yuan/ton $\mathrm{km}$ ) } \\
\hline
\end{tabular}

III. THE COST MINIMIZATION OF THE ELECTRIC COAL TRANSPORT PATH OPTIMIZATION MODEL HYPOTHESIS AND SYMBOL DESCRIPTION

\section{A. Model assumes}

According to the research focus of this paper, and combined with the actual transportation situation, the following instructions are given for the hypothesis of this paper [6].

(1) In accordance with the theme of the optimization of the route of electric coal transportation in this paper, the cost rate is used as the main component of transportation cost accounting for different modes of transportation cost.

(2) Transportation routes and logistics nodes shall be determined in advance in transit. Through the selection of urban nodes passing through transportation, the transportation route and the logistics node identified in advance are utilized to find the cost minimization transportation path.

(3) Freight forwarding mainly refers to the costs incurred by transportation, such as links to transport, which do not include logistics elements such as storage and circulation processing;

(4) The volume cannot be changed in the link of the transport node, which means that there is only one mode of transportation between each pair of nodes;

(5) For the same path, the non-adjacent logistics nodes cannot be transported, and each logistics node does not exist or only has one transport;

(6) The relation between transportation cost and transportation distance is that the size of cost is directly determined by the variable of distance.

\section{B. Symbols to describe}

$\mathrm{Z}, \mathrm{C} 1, \mathrm{C} 2, \mathrm{C} 3$.It is the target function, the internal cost of the transport path and the external cost, and the penalty cost in time.

\section{The optimal model for the cost minimization of the electric coal transport route is established}

The According to transportation path cost minimization analysis, the transport costs within the path $\mathrm{C}_{1}$, transport path of external cost of $\mathrm{C}_{2}$ and punishment cost $\mathrm{C}_{3}$ about transport path cost minimization model, the specific model is as follows [7].

$$
Z=\left(C_{1}+C_{2}+C_{3}\right) \min
$$

The total transportation cost is made up of $\mathrm{C}_{1}, \mathrm{C}_{2}$, and $\mathrm{C}_{3}$. Internal cost $\mathrm{C}_{1}$ consists of the internal cost of transportation and the internal cost of the logistics node. external cost $C_{2}$ is composed of costs outside of the transport path and beyond the logistics node. The composition of $\mathrm{C}_{3}$ mainly consists of the unit time and unit penalty cost that cannot be delivered on time. Constraint condition 1 refers to the only mode of transportation in each logistics node. The constraint condition is that each logistics node can only select one transport mode. The constraint condition 3 makes the transportation cost of the logistics node more than the transport cost of the logistics node, which ensures the transfer demand of the logistics node. The constraint condition four stipulates that the logistics node transport mode and the logistics node transport can only be selected in 0 and 1 ; the constraint condition five stipulates the rationality of logistics capacity, which makes each mode of transportation less than its transportation capacity. Because the logistics node number and type selection of different mode of transportation, constraint condition is established in this paper, in the logistics node is not used to the mode of transportation of the transportation time and transportation cost is infinite [8]. 


\section{MODEL SOlUTION}

According to the above analysis, it is possible to make digital labelling of water port, so as to facilitate the optimization of transportation path, thus achieving the goal of cost minimization.1 - chifeng, 2 - jinzhou, dalian, 3, 4 qinhuangdao, 5 - caofeidian, 6 - Qingdao, 7 - lianyungang, 8 nantong.

According to the model and parameters of power coal transportation route optimization, by using the genetic algorithm at the same time, the operation process of the arithmetic to solve this optimization problem, due to participate in the operation scheme is more, so the operation process of this article is using JAVA main function of system software.

According to the result of JAVA main function operation of the system software is shown in figure 1 below 1 , you can see that for selected 100 times the number of iterations, the data before and after the 80th convergence, and there is no punishment cost, that is to say at this point to the path optimization is most satisfactory results, at the same time, minimize the cost of transportation goals have been realized.

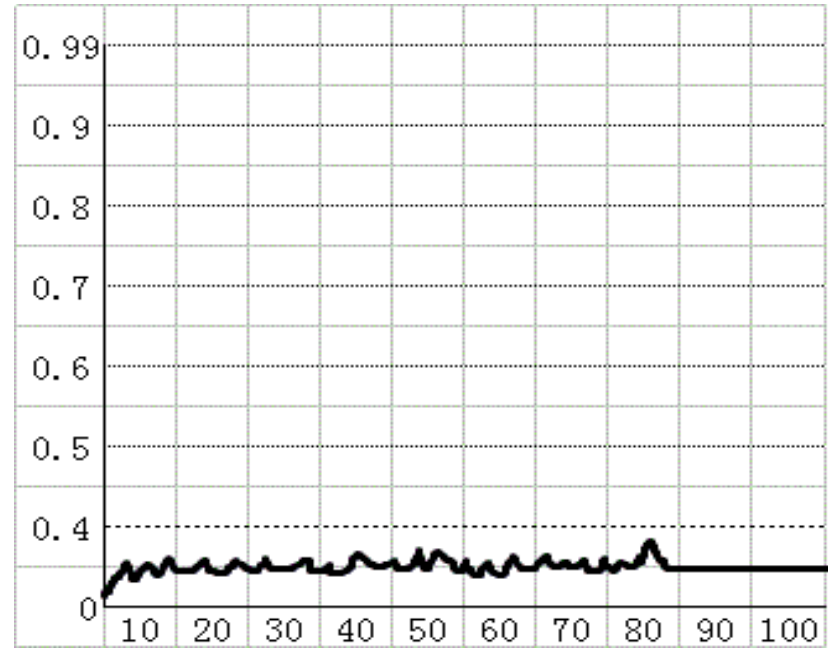

Fig. 1 Iteration frequency distribution of genetic algorithm

The most satisfactory transportation route can be obtained by operation: chifeng -- railway -- jinzhou -- water tranSportati -on -- Nantong. The cost of transportation is shown in table VII.

TABLE VII COSTS OF OPTIMAL TRANSPORT ROUTES

\begin{tabular}{|c|c|c|c|c|c|}
\hline $\begin{array}{c}\text { Point of } \\
\text { departure }\end{array}$ & destination & Transport path & $\begin{array}{c}\text { Internal cost of } \\
\text { transport }\end{array}$ & $\begin{array}{c}\text { Transport } \\
\text { external cost }\end{array}$ & The total cost \\
\hline $\begin{array}{c}\text { Chifeng DHS } \\
\text { coal company }\end{array}$ & $\begin{array}{c}\text { Nantong TSG } \\
\text { power company }\end{array}$ & $\begin{array}{c}\text { Chifeng -- } \\
\text { jinzhou -- } \\
\text { nantong }\end{array}$ & 133.4 & 106.6 & 240 \\
\hline
\end{tabular}

\section{SUMMARY}

Through the above analysis, from the DHS coal company to TSG power generation company's transportation route choice of more than two logistics nodes and the rail and water transport can make minimum transportation cost, and high adaptability to the environment and, at the same time also can control the transportation time limited. In general, it is the most satisfactory solution to the optimal transport path optimization based on cost minimization.

According to the comparison of different transportation schemes in recent years, it can be found that the combination of railway and water transportation can better save transportation cost and realize the optimization of the transportation path of electric coal. Therefore, it can be concluded that the genetic algorithm can achieve the ideal effect for solving the N-P problem.
[1] SUBRAMANIAN A, UCHOA E, PESSO A, etal. Branch-and-cut with lazy separation for the vehicle routing problem with simultaneous pickup and delivery[J]. Computers and Operations Research, 2011, 39(5):338 - 341.

[2] GOKSAL.FP, KARAOGLAN I, ALTIPARMAK F.A hybrid discrete particles warm optimization for vehicle routing problem with simultaneous pickup and delivery $[\mathrm{J}]$. Computers \& Industrial Engineering, 2013, 65(1):39-53.

[3] Polimeni A, Vitetta A. Optimising Waiting at Nodes in Time-Dependent Networks: Cost Functions and Applications [J]. Journal of Optimization Theory \& Applications, 2013, 156(3):805 - 818.

[4] Gasper Artac, Damian F1ynn, Blaz Kladnik, Milos Pantos. A new method for determining the demand reserve offer function [J].Electric Power Systems Research, 2013, (100):55-64.

[5] Levin A., Yovel U. Local search algorithms for multiple-depot vehicle routing and for multiple traveling salesman problems with proved performance guarantees[J].Journal of Combinatorial Optimization, 2014(28):726-747.

[6] Brito J., Martl nez F. J., Moreno J. A., Verdegay J. L. An ACO hybrid metaheuristic for close-open vehicle routing problemswith time windows and fuzzy constraints [J].Applied Soft Compting, 2015, 32: 154-163.

[7] Christian S. Efficient local search on the GPU-Investigations on the vehicle routing problem[J].Journal of Parallel and Distributed Computing, 2013, 73: 14-31.

[8] Nasser A. E-S. Vehicle routing with time windows: An overview of exact, heuristic and metaheuristic methods [J]. Journal of King Saud University (Science), 2010, 22:123-131. 